\title{
INOVAÇÕES E PROJETO POLÍTICO-PEDAGÓGICO: UMA RELAÇÃO REGULATÓRIA OU EMANCIPATÓRIA?
}

\author{
Ilma Passos Alencastro Veiga
}

\begin{abstract}
RE SU M 0: 0 presente artigo discute o significado de inovação e projeto político-pedagógico sob duas perspectivas: como uma ação regulatória ou técnica e como uma ação emancipatória ou edificante. A inovação regulatória significa assumir o projeto político-pedagógico como um conjunto de atividades que vão gerar um produto: um documento pronto e acabado. Nesse caso se deixa de lado o processo de produção coletiva. A inovação de cunho regulatório nega a diversidade de interesses e de atores que estão presentes. Sob a perspectiva emancipatória, a inovação e o projeto político-pedagógico estão articulados, integrando o processo com 0 produto porque o resultado final é não só um processo consolidado de inovação metodológica, na esteira de um projeto construído, executado e avaliado coletivamente, mas um produto inovador que provocará também rupturas epistemológicas.
\end{abstract}

Palavras-chave: Educação. Política educacional. Gestão escolar. Projeto político-pedagógico. Inovação.

\section{Political-Pedagogic innovations and PROJECT: AN EMANCIPATING OR REGULATORY RELATIONSHIP?}

A BSTRA CT: The present paper discusses the meaning of innovations and a political-pedagogic project under two viewpoints: as a regulatory action or technique and as an emancipating or edification action. The regulatory innovation means to assume the politicalpedagogic project as a set of activities that will generate a product: a ready, finished document. In this case, the process of collective pro-

* D Doutora em Educação pela unicamp; pesquisadora associada sênior da Faculdade de Educação da UnB; professora visitante da FACED/ UFU e pesquisadora do CNPQ.

E-mail: ipaveiga@ terra.com.br 
duction is left out. The innovation of a regulatory matrix denies the diversity of interests and actors involved. From the emancipating standpoint, the innovation and the political-pedagogic project are articulated to integrate the process together with the product, because the final result is not only a consolidated process of methodological innovation, in the core of a project built, executed and assessed collectively, but an innovative product that will also provoke epistemological ruptures.

Key words: Education. Educational policies. School management.

Political-pedagogic project. Innovations.

\section{Introdução}

\section{7 consolidação da educação básica e superior como componente da educação escolar e como direito de todos os cidadãos é um objetivo não somente do governo mas de toda a sociedade bra- sileira. Portanto, além de garantir as condições de acesso e permanên- cia de crianças, jovens e adultos nesses componentes educacionais, é preciso construir um projeto político-pedagógico de educação básica e superior de qualidade, comprometido com as múltiplas necessidades sociais e culturais da população.}

Falar em inovação e projeto político-pedagógico tem sentido se não esquecermos qual é a preocupação fundamental que enfrenta o sistema educativo: melhorar a qualidade da educação pública para que todos aprendam mais e melhor. Essa preocupação se expressa muito bem na tríplice finalidade da educação em função da pessoa, da cidadania e do trabalho. D esenvolver o educando, prepará-lo para o exercício da cidadania e do trabalho significam a construção de um sujeito que domine conhecimentos, dotado de atitudes necessárias para fazer parte de um sistema político, para participar dos processos de produção da sobrevivência e para desenvolver-se pessoal e socialmente.

Tenho trabalhado o significado de inovação e projeto com base no entendimento possibilitado por Santos, nas obras U m discurso sobre as ciências (1987), Introdução a uma ciência pós-moderna (1989) e Pela mão de A lice (1997). Nas reflexões que desenvolvo neste artigo, tomarei a inovação e o projeto político-pedagógico como ação regulatória ou técnica e como ação emancipatória ou edificante. 


\section{A inovação regulatória e o projeto político-pedagógico}

A inovação regulatória ou técnica tem suas bases epistemológicas assentadas no caráter regulador e normativo da ciência conservadora, caracterizada, de um lado, pela observação descomprometida, pela certeza ordenada e pela quantificação dos fenômenos atrelados a um processo de mudança fragmentado, limitado e autoritário; e de outro, pelo não-desenvolvimento de uma articulação potencializadora de novas relações entre 0 ser, o saber e 0 agir. Este tipo de inovação "(...) é uma rearticulação do sistema que se apropria das energias emancipatórias contidas na inovação, transformando-a numa energia regulatória" (Leite et al., 1997, p. 10).

A inovação regulatória ou técnica deixa de fora quem inova e, portanto, não é afetado por ela. Há uma separação entre fins e meios, em que se escamoteiam os eventuais conflitos e silenciam as definições alternativas (Santos, 1989) em que se pressupõem definidos os fins e a inovação incide sobre os meios.

Nesta perspectiva, a introdução do novo implica mudança do todo pela mudança das partes. A reforma educacional, preconizada pela LDB, Lei no 9.394/ 96, tem-nos dado alguns exemplos de incitações teóricas a uma participação formal, legitimadora de um controle burocrático cada vez maior sobre as instituições educativas, os professores, os servidores técnico-administrativos e alunos. D essa forma, as políticas públicas constrangem e orientam algumas condições de inovação. Sabe-se hoje, por exemplo, como afirma Benavente, que “(...) as inovações não têm hipóteses de sucesso se os atores não são chamados a aceitar essas inovações e não se envolvem na sua própria construção" (1992, p. 28).

Os processos inovadores continuam a orientar-se por preocupações de padronização, de uniformidade, de controle burocrático, de planejamento centralizado. Se a inovação é instituída, há fortes riscos de que seja absorvida pelas lógicas preexistentes, pelos quadros de referência reguladores.

A estratégia do gestor para inovar pode ser de natureza empíricoracional ou político-administrativa, onde a lógica e a racionalidade de uma inovação justificariam sua difusão e aceitação no sistema (Huberman, 1973; Canário, 1987). Para que isso ocorra, o agente inova- 
Inovações e projeto político-pedagógico...

dor, em geral os professores e coordenadores de curso, ou dirigentes da instituição ou do sistema, lança as idéias e trabalha para sua aceitação e implementação.

Isso significa que os resultados da inovação são transformados em normas e prescrições e, conseqüentemente, sua aplicação é também técnica. Claro que é esta uma das maneiras de proceder; entretanto, se for a única, fortalecerá mais ainda a racionalidade científica que continua respondendo às questões de nosso tempo, de acordo com os moldes das políticas públicas que se enquadram nessa lógica.

Introduzir inovação tem o sentido de provocar mudança, no sistema educacional. De certa forma, a palavra "inovação" vem associada a mudança, reforma, novidade. O "novo" só adquire sentido a partir do momento em que ele entra em relação com o já existente.

Se tomarmos os elementos constitutivos desta concepção de inovação, percebemos, então, que toda inovação se articula em torno da novidade, reforma, racionalidade científica, aplicação técnica do conhecimento, de fora para dentro, ou seja, instituída. Há ritualização e padronização do processo investigativo. De forma geral, as idéias de eficácia, normas, prescrições, ordem, equilíbrio permeiam o processo inovador.

Inovar é, portanto, introduzir algo diferente dentro do sistema, para produzir uma mudança organizacional descontextualizada. Este processo deixa de lado os sujeitos como protagonistas do institucional, desprezando as relações e as diferenças entre eles, não reconhecendo as relações de força entre o institucional e o contexto social mais amplo.

A inovação regulatória ou técnica é instituída no sistema para provocar mudança, mesmo que seja temporária e parcial. Essa mudança não produz um projeto pedagógico novo, produz o mesmo sistema, modificado.

A introdução de uma inovação faz-se, assim, na lógica da dimensão cognitivo-instrumental da ciência e da técnica. Com essa compreensão de inovação, temos construído projetos, sem muita consciência das conseqüências para 0 sistema educativo.

A inovação é uma simples rearticulação do sistema, visando à introdução acrítica do novo no velho. Neste sentido, o projeto políticopedagógico, na esteira da inovação regulatória ou técnica, pode servir para a perpetuação do instituído. Prevalece uma concepção de projeto 
mais preocupado com a dimensão técnica, em detrimento das dimensões política e sociocultural.

A inovação regulatória significa assumir o projeto político-pedagógico como um conjunto de atividades que vão gerar um produto: um documento pronto e acabado. Nesse caso, deixa-se de lado o processo de produção coletiva. Perde-se a concepção integral de um projeto e este se converte em uma relação insumo/ processo/ produto. Pode-se inovar para melhorar resultados parciais do ensino, da aprendizagem, da pesquisa, dos laboratórios, da biblioteca, mas o processo não está articulado integralmente com 0 produto.

A inovação de cunho regulatório ou técnico nega a diversidade de interesses e de atores que estão presentes, porque não é uma ação da qual todos participam e na qual compartilham uma mesma concepção de homem, de sociedade, de educação e de instituição educativa. Trata-se de um conjunto de ferramentas (diretrizes, formulários, fichas, parâmetros, critérios etc.) proposto em nível nacional. Como medidas e ferramentas instituídas legalmente, devem ser incorporadas pelas instituições educativas nos projetos pedagógicos a serem, muitas vezes, financiados, autorizados, reconhecidos e credenciados.

Olhando de modo mais específico, no que concerne ao projeto político-pedagógico, o processo inovador orienta-se pela padronização, pela uniformidade e pelo controle burocrático. 0 projeto político-pedagógico visa à eficácia que deve decorrer da aplicação técnica do conhecimento. Ele tem o cunho empírico-racional ou político-administrativo. Neste sentido, o projeto político-pedagógico é visto como um documento programático que reúne as principais idéias, fundamentos, orientações curriculares e organizacionais de uma instituição educativa ou de um curso.

Enveredar pela compreensão do projeto político-pedagógico como inovação regulatória e técnica implica analisar os principais pressupostos que embasam sua concepção. Assim, a construção do projeto no âmbito da inovação regulatória anda a par com "a reconstituição do campo do poder dentro das escolas, entendido este como espaço de jogo no interior do qual novos atores lutam pelo poder sobre a nova especialização de funções e a interpretação reguladora dos instrumentos de diagnóstico e avaliação" (G omes, 1996, p. 98). Significa dizer que as inovações regulatórias, ao criarem indicadores de desempenho das escolas e 
instituições de ensino superior, acabam por transformar tais indicadores em referenciais para o diagnóstico prévio e para a avaliação de resultados. Para Veiga (2001, p. 47), "o projeto é concebido como um instrumento de controle, por estar atrelado a uma multiplicidade de mecanismos operacionais, de técnicas, de manobras e estratégias que emanam de vários centros de decisões e de diferentes atores".

O movimento que busca a inovação na escola e na instituição de ensino superior, por meio do Programa Fundoescola/ MEc e pela proposta de reforma da educação superior, propiciou o deslocamento da reflexão, que é política em sua gênese e em sua essência, para uma discussão técnica e estéril em sua origem e dotada de pseudoneutralidade em sua essência. A qualidade, que é uma questão de decisão política, passou a ser considerada uma opção sem problemas.

Essa alternativa de gestão do tipo empresarial, centrada no serviço ao cliente, em que se funda a concepção tanto do Plano de Desenvolvimento da Escola (PDE) quanto do Plano de D esenvolvimento Institucional (PDI), orienta-se para o controle e a estabilidade por meio dos planos de ação de curto prazo.

O projeto político-pedagógico, na esteira da inovação regulatória ou técnica, está voltado para a burocratização da instituição educativa, transformando-a em mera cumpridora de normas técnicas e de mecanismos de regulação convergentes e dominadores.

O Plano de Desenvolvimento da Escola (PDE) concretiza-se por meio de uma crescente racionalização do processo de trabalho pedagógico, com ênfase em aspectos como produtividade, competência e controle burocrático. O Plano de D esenvolvimento Institucional (PDI), que se constitui compromisso com o Ministério da Educação, é requisito básico nos atos de credenciamento e recredenciamento da instituição de ensino superior. Para garantia do padrão de qualidade como condição de realização de ensino, a legislação associou processos de avaliação aos de reconhecimento e credenciamento.

O projeto político-pedagógico e a avaliação nos moldes inovadores das estratégias reformistas da educação são, portanto, ferramentas ligadas à justificação do desenvolvimento institucional orientada por princípios da racionalidade técnica, que acabam servindo à regulação e à manutenção do instituído sob diferentes formas. Este é o desafio a ser enfrentado: compreender a educação básica e superior no interior das 
políticas governamentais voltadas para a inovação regulatória e técnica para buscar novas trilhas.

A Figura 1, a seguir, sintetiza as concepções de inovação regulatória ou técnica e projeto político-pedagógico.

\section{Figura 1}

Concepções de Inovação Regulatória ou Técnica e Projeto Político-Pedagógico

\section{Inovação Regulatónia ou Técnica}

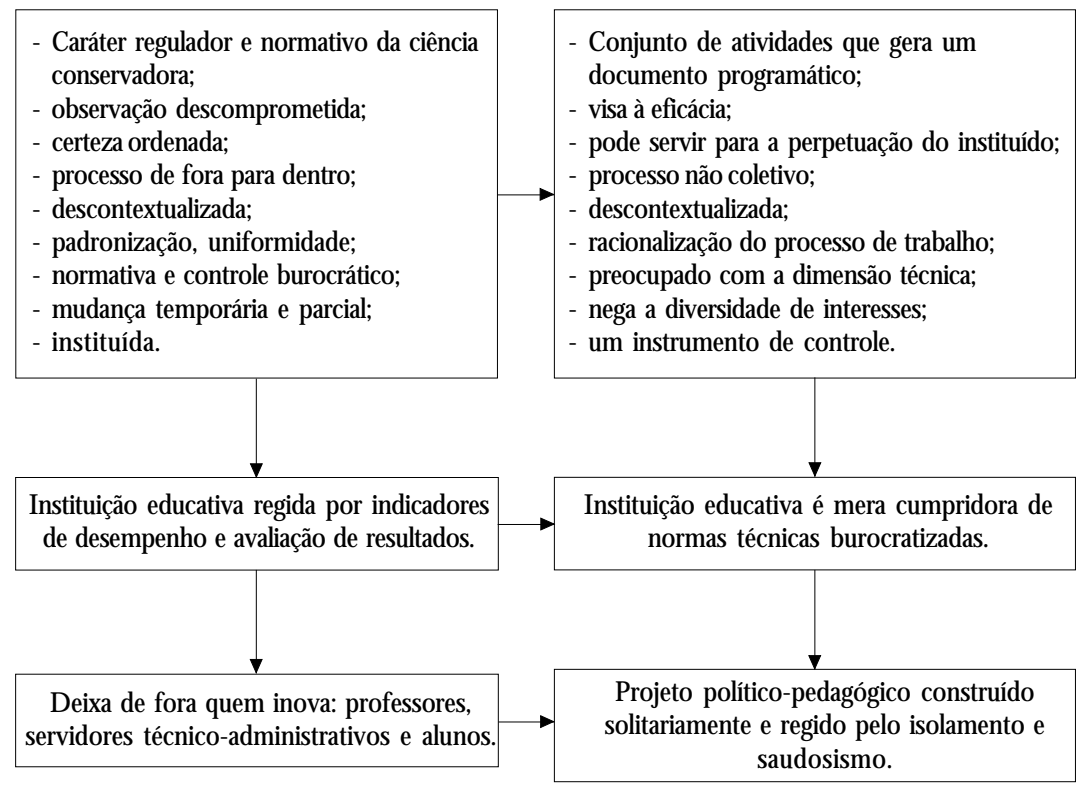

\section{0 projeto político-pedagógico como inovação emancipatória ou edificante}

É importante que explicite meu entendimento de inovação emancipatória ou edificante para que se possa compreender as bases em 
que se assenta o projeto político-pedagógico. Parto do princípio de que a inovação emancipatória ou edificante não pode ser confundida com evolução, reforma, invenção ou mudança. Lucarelli considera-a uma “(...) ruptura do status quo com o institucional” (Lucarelli et al., 1994, p. 10), significando a construção dos projetos pedagógicos para atingir objetivos, no âmbito de uma determinada instituição educativa.

Considerando a inovação uma produção humana, parto da idéia de que suas bases epistemológicas estão alicerçadas no caráter emancipador e argumentativo da ciência emergente. A inovação procura maior comunicação e diálogo com os saberes locais e com os diferentes atores e realiza-se em um contexto que é histórico e social, porque humano. A ciência emergente opõe-se às clássicas dicotomias entre ciências naturais/ ciências sociais, teoria/ prática, sujeito/ objeto, conhecimento/ realidade. Trata-se, portanto, de buscar a superação da fragmentação das ciências e suas implicações para a vida do homem e da sociedade.

Neste sentido, a inovação emancipatória ou edificante tem sempre “(...) lugar numa situação concreta em que quem aplica está existencial, ética e socialmente comprometido com o impacto da aplicação" (Santos, 1989, p. 158). Não há separação entre fins e meios, uma vez que a ação incide sobre ambos pois "(...) os fins só se concretizam na medida em que discutem os meios adequados à situação concreta” (idem, ibid.).

É fácil compreender que a intencionalidade permeia todo o processo inovador e, conseqüentemente, o processo de construção, execução e avaliação do projeto político-pedagógico. Os processos inovadores lutam contra as formas instituídas e os mecanismos de poder. É um processo de dentro para fora. Essa visão reforça as definições emergentes e alternativas da realidade. Assim, ela deslegitima as formas institucionais, a fim de propiciar a argumentação, a comunicação e a solidariedade.

Identificar a estratégia do gestor no projeto político-pedagógico é, antes de mais nada, localizar os elementos que propiciam a investigaçãoação que exige novas formas de organização, a combinação e utilização de várias técnicas investigativas. É certo que as inovações se desenvolvem na prática cotidiana, ou seja, realizam-se no processo de construção/ implementação dos projetos pedagógicos. D essa forma, os resultados da inovação ultrapassam as questões técnicas sem prescindir delas e opõem-se às orientações da racionalidade da ciência conservadora (Santos, 1987). 
Em resumo, a inovação emancipatória ou edificante pressupõe uma ruptura que, acima de tudo, predisponha as pessoas e as instituições para a indagação e para a emancipação. Conseqüentemente, a inovação não vai ser um mero enunciado de princípios ou de boas intenções...

A inovação emancipatória ou edificante é de natureza ético-social e cognitivo-instrumental, visando à eficácia dos processos formativos sob a exigência da ética. A inovação é produto da reflexão da realidade interna da instituição referenciada a um contexto social mais amplo.

Este ponto é de vital importância para se avançar na construção de um projeto político-pedagógico que supere a reprodução acrítica, a rotina, a racionalidade técnica, que considera a prática um campo de aplicação empirista, centrada nos meios.

Organizar as atividades-fim e meio da instituição educativa, por meio do projeto político-pedagógico sob a ótica da inovação emancipatória e edificante, traz consigo a possibilidade de alunos, professores, servidores técnico-administrativos unirem-se e separarem-se de acordo com as necessidades do processo.

O projeto político-pedagógico, na esteira da inovação emancipatória, enfatiza mais o processo de construção. É a configuração da singularidade e da particularidade da instituição educativa. Bicudo afirma que a importância do projeto reside "no seu poder articulador, evitando que as diferentes atividades se anulem ou enfraqueçam a unidade da instituição" (2001, p. 16). Inovação e projeto político-pedagógico estão articulados, integrando o processo com o produto porque o resultado final não é só um processo consolidado de inovação metodológica no interior de um projeto político-pedagógico construído, desenvolvido e avaliado coletivamente, mas é um produto inovador que provocará também rupturas epistemológicas. Não podemos separar processo de produto.

Sob esta ótica, o projeto é um meio de engajamento coletivo para integrar ações dispersas, criar sinergias no sentido de buscar soluções alternativas para diferentes momentos do trabalho pedagógico-administrativo, desenvolver o sentimento de pertença, mobilizar os protagonistas para a explicitação de objetivos comuns definindo o norte das ações a serem desencadeadas, fortalecer a construção de uma coerência comum, mas indispensável, para que a ação coletiva produza seus efeitos.

Costa \& Madeira (1997) consideram alguns elementos conceituais do projeto político-pedagógico: 
a) o projeto diz respeito à concepção de escolas socialmente determinadas e referidas ao campo educativo;

b) na fase de reflexão é que a instituição define e assume uma identidade que se expressa por meio do projeto;

c) o projeto serve de referente à ação de todos os agentes que intervêm no ato educativo;

d) o desenvolvimento do projeto implica a existência de um conjunto de condições, sem as quais ele poderá estar condenado a tornar-se apenas mais um "formulário administrativo";

e) a participação só poderá ser assegurada se o projeto perseguir os objetivos dos atores e grupos envolvidos no ato educativo, em sua globalidade.

O projeto político-pedagógico dá o norte, o rumo, a direção; “Ele possibilita que as potencialidades sejam equacionadas, deslegitimando as formas instituídas" (Veiga, 2000, p. 192).

Sob esta ótica, o projeto político-pedagógico apresenta algumas características fundamentais:

a) É um movimento de luta em prol da democratização da escola que não esconde as dificuldades e os pessimismos da realidade educacional, mas não se deixa levar por esta, procurando enfrentar o futuro com esperança em busca de novas possibilidades e novos compromissos. É um movimento constante para orientar a reflexão e ação da escola.

b) Está voltado para a inclusão a fim de atender a diversidade de alunos, sejam quais forem sua procedência social, necessidades e expectativas educacionais (Carbonell, 2002); projeta-se em uma utopia cheia de incertezas ao comprometer-se com os desafios do tratamento das desigualdades educacionais e do êxito e fracasso escolar.

c) Por ser coletivo e integrador, o projeto, quando elaborado, executado e avaliado, requer o desenvolvimento de um clima de confiança que favoreça o diálogo, a cooperação, a negociação e o direito das pessoas de intervirem na tomada de decisões que afetam a vida da instituição educativa e de comprometerem-se com a ação. 
O projeto não é apenas perpassado por sentimentos, emoções e valores. Um processo de construção coletiva fundada no princípio da gestão democrática reúne diferentes vozes, dando margem para a construção da hegemonia da vontade comum. A gestão democrática nada tem a ver com a proposta burocrática, fragmentada e excludente; ao contrário, a construção coletiva do projeto político-pedagógico inovador procura ultrapassar as práticas sociais alicerçadas na exclusão, na discriminação, que inviabilizam a construção histórico-social dos sujeitos.

d) Há um vínculo muito estreito entre autonomia e projeto político-pedagógico. A autonomia possui o sentido sociopolítico e está voltada para 0 delineamento da identidade institucional. A identidade representa a substância de uma nova organização do trabalho pedagógico. A autonomia anula a dependência e assegura a definição de critérios para a vida escolar e acadêmica. Autonomia e gestão democrática fazem parte da especificidade do processo pedagógico.

e) A legitimidade de um projeto político-pedagógico está estreitamente ligada ao grau e ao tipo de participação de todos os envolvidos com o processo educativo, o que requer continuidade de ações.

f) Configura unicidade e coerência ao processo educativo, deixa claro que a preocupação com o trabalho pedagógico enfatiza não só a especificidade metodológica e técnica, mas volta-se também para as questões mais amplas, ou seja, a das relações da instituição educativa com 0 contexto social.

Construir o projeto político-pedagógico para a instituição educativa significa enfrentar o desafio da inovação emancipatória ou edificante, tanto na forma de organizar o processo de trabalho pedagógico como na gestão que é exercida pelos interessados, o que implica o repensar da estrutura de poder.

A instituição educativa não é apenas uma instituição que reproduz relações sociais e valores dominantes, mas é também uma instituição de confronto, de resistência e proposição de inovaç̧ões. A inovação educativa deve produzir rupturas e, sob essa ótica, ela procura romper com a clássica cisão entre concepção e execução, uma divisão própria da organização do trabalho fragmentado. 
Nesta perspectiva, o projeto pedagógico inovador amplia a autonomia da escola e esta? "nunca é empreendida a partir do isolamento e do saudosismo, mas a partir do intercâmbio e da cooperação permanente como fonte de contraste e enriquecimento" (Carbonell, 2002, p. 21). A Figura 2, a seguir, ilustra as concepções.

\section{Figura 2}

Concepções de Inovação Emancipatória ou Edificante e Projeto Político-Pedagógico

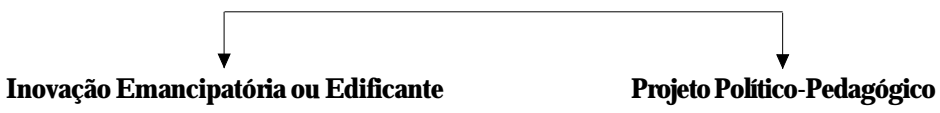

- Não é reforma, invenção ou mudança; pressupõe ruptura;

- é produção humana;

- alicerçada no caráter emancipador e argumentativo da ciência emergente;

- busca superar a fragmentação das ciências;

- não há separação de fins e meios;

- deslegitima as formas instituídas.

- É um movimento de luta em prol da democratização;

- está voltado para a inclusão;

- favorece o diálogo, a cooperação;

- há vínculo entre autonomia e projeto político-pedagógico;

- legitimidade ligada ao grau de participação dos envolvidos;

- configura unicidade e coerência ao processo educativo.

Instituição educativa repensa a estrutura de poder, suas relações sociais e seus valores.

Instituição educativa é uma instituição de confronto, de resistência e de proposição de inovações.

Professores, servidores técnicoadministrativos e alunos unem-se e separam-se de acordo com a necessidade do processo; há protagonismos.
Projeto político-pedagógico construído coletivamente é regido pelo intercâmbio e pela cooperação. 


\section{Algumas considerações...}

Sem a pretensão de concluir, é preciso entender que o projeto pedagógico é caracterizado como ação consciente e organizada. O projeto deve romper com 0 isolamento dos diferentes segmentos da instituição educativa e com a visão burocrática, atribuindo-lhes a capacidade de problematizar e compreender as questões postas pela prática pedagógica.

A elaboração do projeto político-pedagógico sob a perspectiva da inovação emancipatória é um processo de vivência democrática à medida que todos os segmentos que compõem a comunidade escolar e acadêmica participam dela, tendo compromisso com seu acompanhamento e, principalmente, nas escolhas das trilhas que a instituição irá seguir. D essa forma, caminhos e descaminhos, acertos e erros não serão mais da responsabilidade da direção ou da equipe coordenadora, mas do todo que será responsável por recuperar o caráter público, democrático e gratuito da educação estatal, no sentido de atender os interesses da maioria da população.

Para modificar sua própria realidade cultural, a instituição educativa deverá apostar em novos valores. Em vez da padronização, propor a singularidade; em vez de dependência, construir a autonomia; em vez de isolamento e individualismo, o coletivo e a participação; em vez da privacidade do trabalho pedagógico, propor que seja público; em vez de autoritarismo, a gestão democrática; em vez de cristalizar o instituído, inová-lo; em vez de qualidade total, investir na qualidade para todos.

É fundamental que se entenda, de maneira tão clara quanto possível, a natureza geral dessa forma de conceber o projeto político-pedagógico, fundado na concepção de inovação emancipatória ou edificante. Por um lado, o projeto é um meio que permite potencializar o trabalho colaborativo e o compromisso com objetivos comuns; por outro, sua concretização exige rupturas com a atual organização do trabalho e 0 funcionamento das instituições educativas.

As noções de inovação e projeto político-pedagógico assumidas neste artigo diferem da concepção conservadora e regulatória como rearranjo de situações externas à situação inovada. Cabe a nós, educadores e pesquisadores, o papel fundamental no sentido de clarear e 
Inovações e projeto político-pedagógico...

desvelar as concepções que respaldam as lógicas de inovação e do projeto político-pedagógico.

Recebido em agosto de 2003 e aprovado em setembro de 2003.

\section{Referências bibliográficas}

BENAVENTE, A. As ciências da educação e a inovação das práticas educativas. In: SOCIEDADE PORTUGUESA DE CIENCIAS DA EDUCAÇÃO. D ecisões nas políticas e práticas educativas. Porto: SPCE, 1992.

BICUD 0, M.A.V. Reestruturação acadêmica e desenvolvimento regional. E ducação Brasileira, Brasília, D F, v. 23, n. 46, p. 11-22, jan./ fev. 2001.

CANÁRIO, R. A inovação como processo permanente. Revista E ducação, Lisboa, v. 1, n. 2, p. 17-22, 1987.

CARBO NELL, J. A aventura de inovar: a mudança na escola. Porto Alegre: ARTMED, 2002.

CO STA, A.C.; MAD EIRA, A.I. A construção do projeto educativo de escola: estudos de caso no ensino básico. Lisboa: Instituto de Inovação Educacional, 1997.

HUBERMAN, A.M. C omo se realizam as mudanças em educação. Paris: UNESCO, 1973.

LEITE, D.B.C. et al. Inovação na zona cinzenta da transição. C adernos de E ducação, Pelotas, v. 6, n. 8, jun. 1997.

LUCARELLI, E. et al. Teoría y práctica como innovación en docencia. Buenos Aires: FFyL/ UBA, 1994.

SANTO S, B.S. U m discurso sobre as ciências. Lisboa: Afrontamento, 1987.

SANTO S, B.S. Introdução a uma ciência pós-moderna. Rio de Janeiro: G raal, 1989. 
SANTOS, B.S. Pela mão de A lice: o social e o político na pós-modernidade. 4. ed. São Paulo: Cortez, 1997.

VEIGA, I.P.A. Projeto político-pedagógico: novas trilhas para a escola. In: VeIgA, I.P.A.; FonseCA, M. (O rg.). D imensões do projeto político-pedagógico: novos desafios para a escola. Campinas: Papirus, 2001. VEIG A, I.P. A. Projeto político-pedagógico: continuidade ou transgressão para acertar? In: CASTANHO, M.E.L.M.; CASTANHO, S. (O rg.). 0 que há de novo na educação superior: do projeto pedagógico à prática transformadora. Campinas: Papirus, 2000. 